\title{
Examining the seismic behaviour of partially saturated sand using centrifuge shaking table tests
}

\author{
Zitao Zhang ${ }^{1, *}$, Jianzhang Xiao ${ }^{1}$, Yingqi $\mathrm{Wei}^{1}$, Hong Cai ${ }^{1}$, Jianhui Liang $^{1}$, Jun Yan $^{1}$ \\ ${ }^{1}$ State Key Laboratory of Simulation and Regulation of Water Cycle in River Basin, China Institute of Water Resources and Hydropower \\ Research, Beijing, China
}

\begin{abstract}
Similar to fully saturated sand, the partially saturated sand can also liquefy under certain conditions during earthquakes. This study aims to characterize the seismic behaviour of partially saturated sand. Centrifuge shaking table tests were performed using the IWHR horizontal-vertical centrifuge shaker. The experimental results indicate that the liquefaction resistance of the partially saturated sand increases with decreasing the degree of saturation and with increasing the initial effective stress right before shaking. The boundary between the liquefied and un-liquefied sand becomes deeper and deeper during shaking.
\end{abstract}

\section{Introduction}

The increase of liquefaction resistance with decreasing the degree of saturation $\left(\mathrm{S}_{\mathrm{r}}\right)$ in sandy soil has been wellknown. The phenomenon has been demonstrated by many researchers through element tests such as triaxial cyclic shear tests (e.g., [1]), cyclic simple shear tests (e.g., [2]) and cyclic torsional shear tests (e.g., [3]). As indicated in Yoshimi et al. ([3]), the liquefaction resistance is about three times that at full saturation as the degree of saturation decreases to $70 \%$. One of the underlying mechanisms governing the behavior is that the air in the soil deposits can absorb the generated excess pore pressures by reducing its volume ([4]). Therefore, decreasing the degree of saturation of sand deposits through lowering the ground water table or through injecting air bubbles into the pores between sand particles might be an effective earthquake resistant measure, and some attempts based on the idea have been performed.

Even though the partially saturated sand has a relatively larger liquefaction resistance, it can still liquefy under certain conditions, e.g., when the earthquake shaking is strong enough. Such liquefaction of partially saturated sand has been observed during historical earthquakes. For example, mudflow type slope failures of partially saturated sandy soil which resulted from soil liquefaction were reported in 2001 El Salvador and 2003 Japan earthquakes ([5-6]). The associated experimental study shows that both the pore air and water pressure build up in the partially saturated sand subjected to a seismic loading. The liquefaction state is established when both the pore air and water pressure become equal with the initial total pressure ([7]). In addition, the liquefaction resistance of partially saturated sand is influenced by the initial effective stress and the degree of saturation. The aforementioned experimental studies based on element tests revealed the basis characteristics of the seismic behavior of partially saturated sand. However, due to the limitations of such element tests, centrifuge model tests, which can simulate the real stress distribution and drainage condition in the field, are still needed to characterize such a behavior.

This study aims to characterize the seismic behavior of partially saturated sand using centrifuge shaking table tests. Four sandy ground with different degree of saturation were subjected to the same horizontal-vertical seismic loading during the Centrifuge shaking table tests. Miniature water pressure sensors were adopted to measure the variation in the excess pore water pressure during earthquake shaking. The experimental details will be firstly introduced in the following text, followed by the experimental results and discussions. As last, some concluding remarks will be presented.

\section{Experimental details}

The centrifuge shaking table tests were performed using the IWHR (Institute of Water Resources and Hydropower Research) centrifuge horizontal-vertical shaker (Model R500B, Anco Engineers, Inc., Boulder, Colorado, USA). The shaking table can vibrate in both horizontal and vertical directions simultaneously at a centrifugal acceleration up to $100 \mathrm{~g}$. Details of the centrifuge shaker can be found in Hou et al. ([8]).

Fig. 1 presents the elevation view of the centrifuge model. The dimensions of the inner space of the rigid container are $750 \mathrm{~mm} \times 200 \mathrm{~mm}$ on plan $\times 400 \mathrm{~mm}$ height. The inner space of the container was divided into four zones with similar sizes by impermeable division plates. Four sandy ground models with different saturation conditions were prepared in these zones. Each model had a length of $180-190 \mathrm{~mm}$, a width of $200 \mathrm{~mm}$ and a depth of $150 \mathrm{~mm}$. At a $40 \mathrm{~g}$ gravitational

\footnotetext{
Corresponding author: zhangzt@iwhr.com
} 


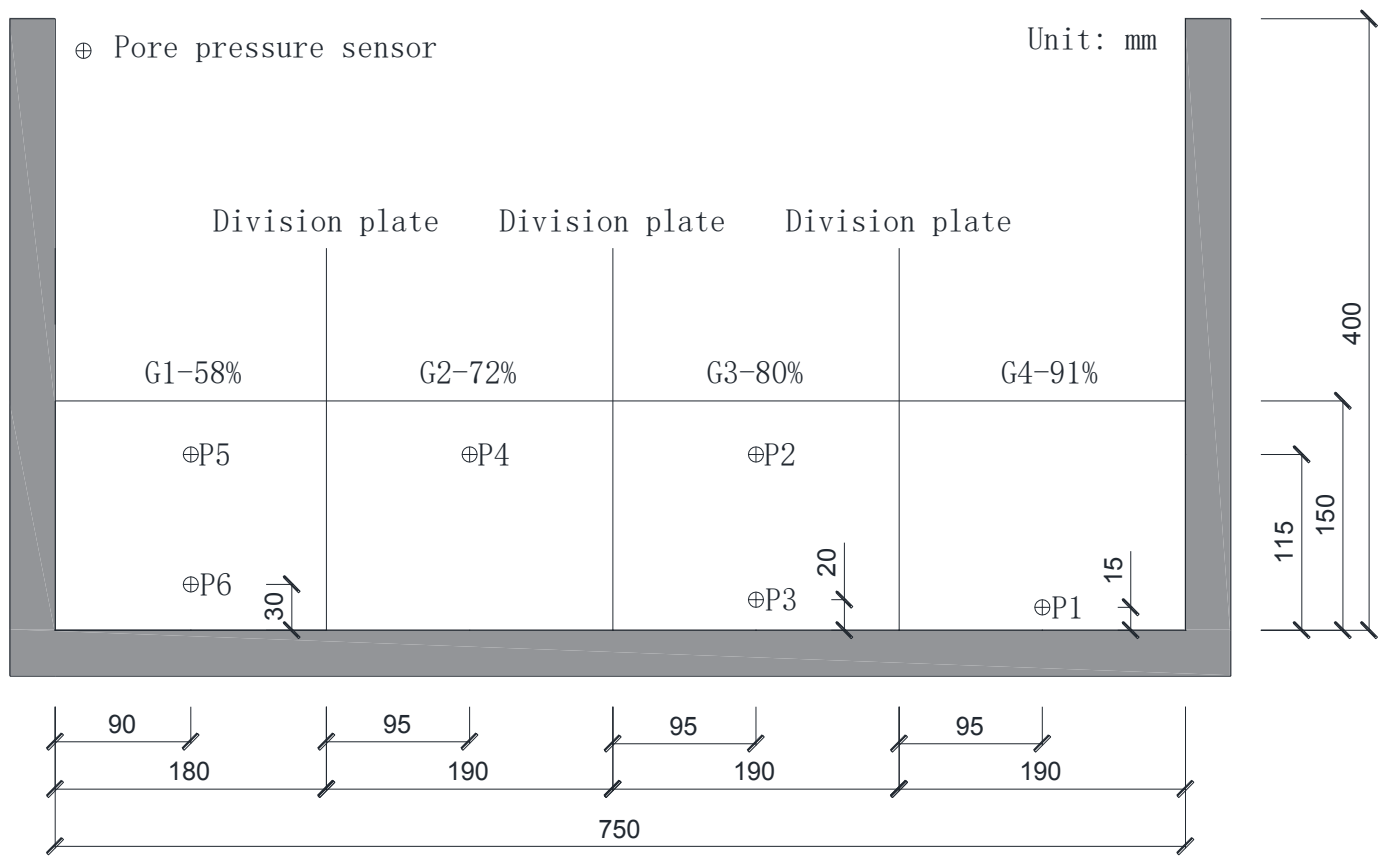

Fig. 1. Elevation view of the centrifuge model

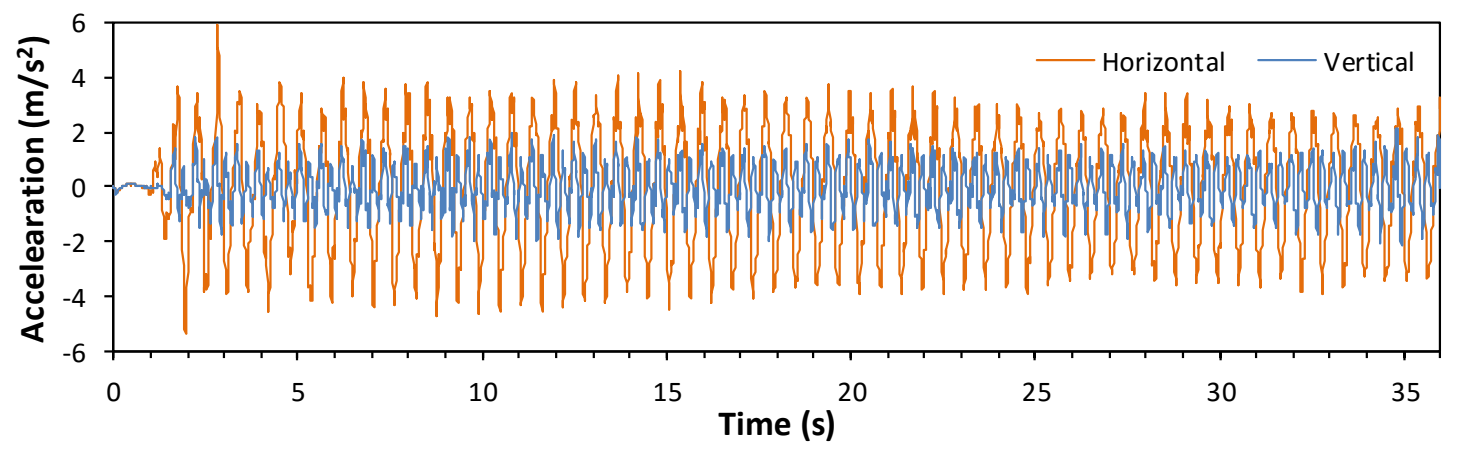

Fig. 2. Acceleration time histories of the input motion of the input motion in the horizontal and vertical directions

acceleration field, each model simulated a prototype sand deposit of $7.2-7.6 \mathrm{~m}$ in length, $8 \mathrm{~m}$ in width and 6 $\mathrm{m}$ in depth. To ease the discussion, these sandy ground models are denoted by G1-58\%, G2-72\%, G3-80\% and G4-91\%. The number in each denotation shows the average degree of saturation of that model.

The sand used in all the models was the standard Pingtan sand from Fujian, China, which is a silica sand and has a rounded to sub-rounded particle shape. About $90 \%$ of the particle diameters fell in the range of $0.25-0.65$ $\mathrm{mm}$, and the median diameter $\mathrm{d}_{50}$ is $0.34 \mathrm{~mm}$. The maximum and minimum dry densities of the sand are 1.74 and $1.43 \mathrm{~g} / \mathrm{cm}^{3}$, respectively. The specific gravity of the sand particles is 2.643. Each sandy ground model was prepared layer by layer. The dry sand was initially mixed with water, and the mixture was then gently transferred to the specific zone. Afterwards, the wet sand was tempered to make the dry density reach $1.54 \mathrm{~g} / \mathrm{cm}^{3}$ or the relative density equal approximately $40 \%$. During the preparation, miniature water pressure sensors were installed to monitor variations in the pore water pressure during shaking. To reduce the boundary effect, all the sensors were installed along the central line of each model.

After sample preparation, the container was transferred to the centrifuge shaking table, and then the sandy ground models were subjected to a $40 \mathrm{~g}$ gravitational acceleration field. When the pore water pressure was stable, all the sandy ground models were subjected to the same horizontal-vertical seismic loading simultaneously. The measurements from water pressure sensors were constantly collected with a sampling frequency of $1000 \mathrm{~Hz}$ during shaking. Figs. 2 and 3 present the acceleration histories and Fourier Spectra of the input motion measured by the accelerometers installed on the shaking table.

Unless otherwise indicated, all the magnitudes are in prototype scale in the following text. The horizontal peak acceleration in each cycle falls in the range of $2 \sim 4 \mathrm{~m} / \mathrm{s}^{2}$ (i.e., $0.2 \sim 0.4 \mathrm{~g}$ ), while the vertical value is in the range of $1 \sim 2 \mathrm{~m} / \mathrm{s}^{2}$ (i.e., $0.1 \sim 0.2 \mathrm{~g}$ ). The main frequencies in the horizontal and vertical directions respectively are 1.75 and $3.5 \mathrm{~Hz}$.

\footnotetext{
* Corresponding author: zhangzt@iwhr.com
} 


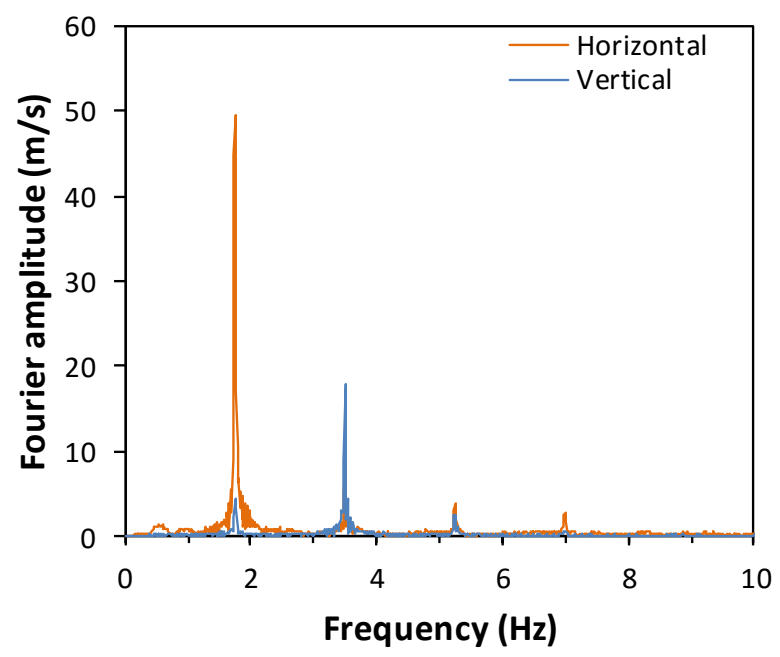

Fig. 3. Fourier spectra of the input motion in the horizontal and vertical directions

\section{Experimental results and discussions}

The experimental results on the soil water characteristic curve of clean sands similar to the one used in this study demonstrated that the suction value, i.e., (pore air pressure $\mathrm{p}_{\mathrm{a}}$ - pore water pressure $\mathrm{p}_{\mathrm{w}}$ ) is smaller than $4 \mathrm{kPa}$ when the degree of saturation is larger than $50 \%$. Hence, to ease the discussion, it is assumed that the air and water pressure, i.e., $\mathrm{p}_{\mathrm{a}}$ and $\mathrm{p}_{\mathrm{w}}$, at a given location are identical. Hence, the variation in the pore air pressure during shaking can be reflected by the measured pore water pressure as shown later.

Since the seismic behavior is mainly affected by the initial condition in terms of the initial degree of saturation and effective stresses right before shaking, the initial condition is essential for analyzing the seismic behavior during shaking. Therefore, the initial condition is firstly discussed in the following text, followed by the variations in the excess pore water pressure during shaking.

\subsection{Initial condition right before shaking}

Due to the reduction in the air volume and permeability of water during spinning up of the models, the distribution of the degree of saturation in the sandy models before shaking is different from that before spinning up. Such variation in the condition of each model is simplified as lowering of the water table during spinning up. Hence, the upper part of the model above the water table is regarded as dry sand, while the lower part of the model is partially saturated sand with a degree of saturation higher than the designed value. Fig. 4 presents the initial pore water pressure, $\mathrm{p}_{\mathrm{w} 0}$, measured before shaking. For the models $\mathrm{G} 3-80 \%$ and $\mathrm{G} 4-91 \%$, it seems that the water table is still at a prototype depth of 0 . However, the water tables in the $\mathrm{G} 1-58 \%$ and $\mathrm{G} 2-72 \%$ in the depths of $1.2 \mathrm{~m}$ and $0.7 \mathrm{~m}$, respectively. The degrees of saturation in the lower parts of $\mathrm{G} 1-58 \%$ and $\mathrm{G} 2-72 \%$ are respectively $73 \%$ and $81 \%$. To ease the discussion, the two models are re-denoted as
G1-58\%(73\%) and G2-72\%(81\%). The initial properties of the models are summarized in Table 1.

\section{Initial pore water pressure ( $\mathrm{kPa})$}

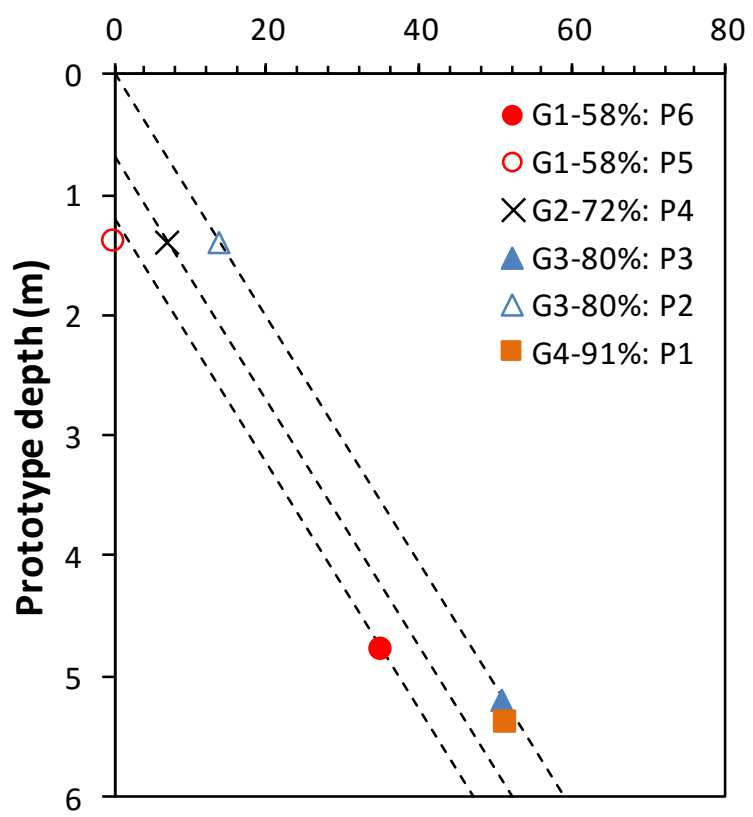

Fig. 4. Initial pore water pressure measured before the shaking

Table 1. Initial properties of the centrifuge sandy ground models

\begin{tabular}{|c|c|c|c|c|c|c|}
\hline \multirow{2}{*}{$\begin{array}{l}\text { Model } \\
\text { No. }\end{array}$} & \multirow{2}{*}{$\begin{array}{c}\text { dwT } \\
0 \\
\text { (m) }\end{array}$} & \multirow{2}{*}{$\begin{array}{c}\mathrm{S}_{\mathrm{r} 0} \\
(\% \\
)\end{array}$} & \multicolumn{4}{|c|}{$\begin{array}{l}\text { Initial condition at sensor } \\
\text { locations }\end{array}$} \\
\hline & & & $\begin{array}{l}\text { Senso } \\
\text { r No. }\end{array}$ & $\begin{array}{l}\text { Dept } \\
\text { h (m) }\end{array}$ & $\begin{array}{c}\sigma_{\mathrm{v} 0} \\
(\mathrm{kPa} \\
)^{\prime}\end{array}$ & $\begin{array}{c}\mathrm{p}_{\mathrm{w} 0} \\
(\mathrm{kPa} \\
)\end{array}$ \\
\hline \multirow{2}{*}{$\begin{array}{c}\text { G1- } \\
58 \%(73 \% \\
)\end{array}$} & \multirow{2}{*}{1.2} & \multirow{2}{*}{73} & P5 & 1.4 & 0 & 21.5 \\
\hline & & & P6 & 4.8 & 35.0 & 47.5 \\
\hline $\begin{array}{c}\mathrm{G} 2- \\
72 \%(81 \% \\
)\end{array}$ & 0.7 & 81 & P4 & 1.4 & 16.3 & 7 \\
\hline \multirow{2}{*}{ G3-80\% } & \multirow{2}{*}{0} & \multirow{2}{*}{80} & P2 & 1.4 & 11.8 & 14 \\
\hline & & & P3 & 5.2 & 44.1 & 51 \\
\hline G4-91\% & 0 & 91 & P1 & 5.4 & 49.4 & 51 \\
\hline
\end{tabular}

Note: $\mathrm{d}_{\mathrm{WT} 0}$ is the depth of the water table right before shaking; $\mathrm{S}_{\mathrm{r} 0}$ is the degree of saturation of the part below the water table right before shaking

In addition to the initial degree of saturation, the initial effective stress, $\sigma_{\mathrm{v} 0}$ ' is also essential for further analysis during shaking. Based on Bishop et al. ([9]), the effective vertical stress $\sigma_{\mathrm{v}}{ }^{\prime}$ is given by

$$
\sigma_{v}^{\prime}=\left(\sigma_{v}-p_{a}\right)+\chi\left(p_{a}-p_{w}\right)
$$

where $\sigma_{\mathrm{v}}$ and $\chi$ represent the total vertical stress and material parameter, respectively. In this study, $\chi$ is taken as $\mathrm{S}_{\mathrm{r}} / 100$. Based on the distribution of the degree of saturation along the depth presented in Table $1, \sigma_{\mathrm{v} 0}$ and $\chi$ can be obtained. As $p_{w}$ is directly measured and $p_{a}$ is assumed equal $\mathrm{p}_{\mathrm{w}}, \sigma_{\mathrm{v} 0}$ ' can be calculated. The initial 
effective vertical stress $\sigma_{\mathrm{v} 0}$ and pore water pressure $\mathrm{p}_{\mathrm{w} 0}$ right before shaking are also presented in Table 1 .

\subsection{Variations in the excess pore water pressure ratio during shaking}

As it is assumed that $p_{a}=p_{w}$, the excess pore water pressure ratio $R_{\text {ew }}$ ratio, which is the ratio of the excess pore water pressure $\left(p_{w}-p_{w 0}\right)$ over the initial effective vertical stress $\left(\sigma_{\mathrm{v} 0}{ }^{\prime}\right)$, can be used to describe the state of the sand. When $\mathrm{R}_{\mathrm{ew}}=1$, the sand liquefies. Fig. 5 presents the variation in $R_{e w}$ for the soil with different initial effective vertical stresses at similar degree of saturation. Since the degree of saturation at the locations of the sensors P2, P3 and P4 are similar, i.e., $80 \sim 81 \%$, the variations in $R_{e w}$ at those locations are selected to demonstrate the influence of the initial effective vertical stress. The values of $\sigma_{\mathrm{v} 0}$ ' associated with P2, P3 and P4 are $11.8 \mathrm{kPa}, 44.1 \mathrm{kPa}$ and $16.3 \mathrm{kPa}$, respectively. Those values are also marked in Fig. 5. The figure shows the buildup of excess pore water and air pressure during shaking, and the sand at those locations eventually liquefies.

For P2 and P3 located in the same sandy ground model, the shallower sand at a depth of $1.4 \mathrm{~m}$ with a relatively small effective stress liquefies at about $3 \mathrm{~s}$, while the deeper sand at a depth of $5.2 \mathrm{~m}$ liquefies about $7 \mathrm{~s}$ later. In addition, even though $\mathrm{P} 2$ and $\mathrm{P} 4$ are at the same depth, the sand at those locations does not liquefy simultaneously. The sand with a larger initial effective stress at P4 liquefies 2s later than the liquefaction time of $\mathrm{P} 2$ and $5 \mathrm{~s}$ earlier than that of $\mathrm{P} 3$. This clearly indicates the effect of initial effective stress on the liquefaction resistance of the partially saturated sand. Moreover, the measurements from P2 and P3 reflect that the boundary between the liquefied and un-liquefied parts becomes deeper and deeper during shaking for a specific sandy ground, which can hardly be simulated by element tests. This proves the efficiency of centrifuge shaking table tests to reproduce the seismic behavior observed in the field.

Fig. 6 presents the variations in $\mathrm{R}_{\mathrm{ew}}$ for the soil with different degree of saturation at similar initial effective vertical stresses (i.e., $35 \sim 50 \mathrm{kPa}$ ). For the sand with a degree of saturation larger than $80 \%$, the sand liquefies at about 10 seconds. When the degree of saturation becomes smaller, i.e., $73 \%$, the sand does not reach the liquefaction state during the whole shaking process. Hence, the liquefaction resistance increases with decreasing degree of saturation. The result is consistent with that obtained by element tests.

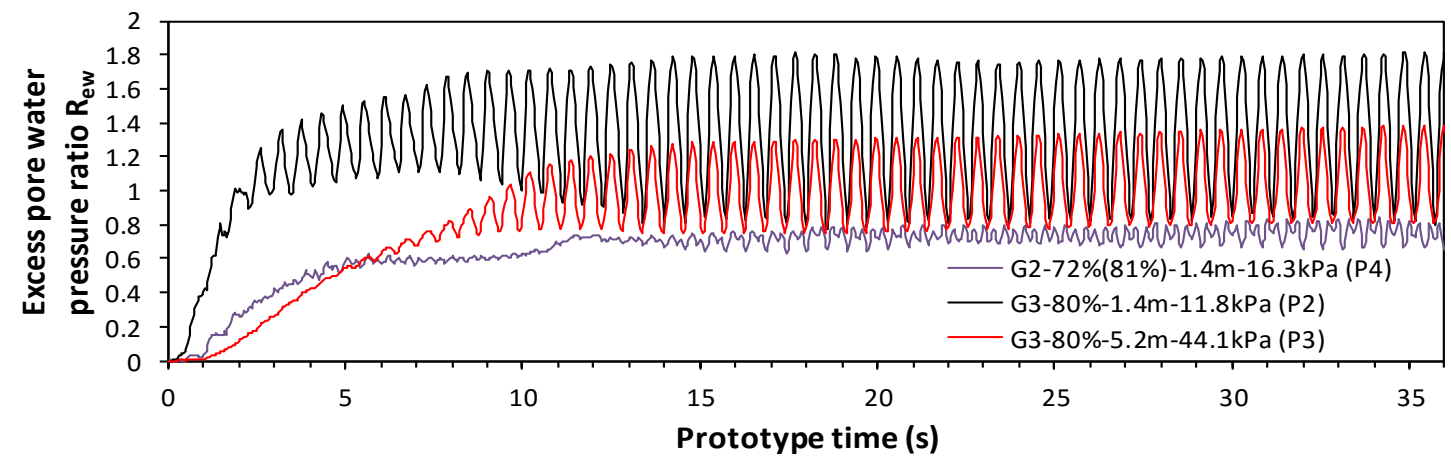

Fig. 5. Variations in the excess pore water pressure ratio $\mathrm{R}_{\mathrm{ew}}$ for the soil with different initial effective vertical stresses at similar degree of saturation (i.e., $80 \sim 81 \%$ ).

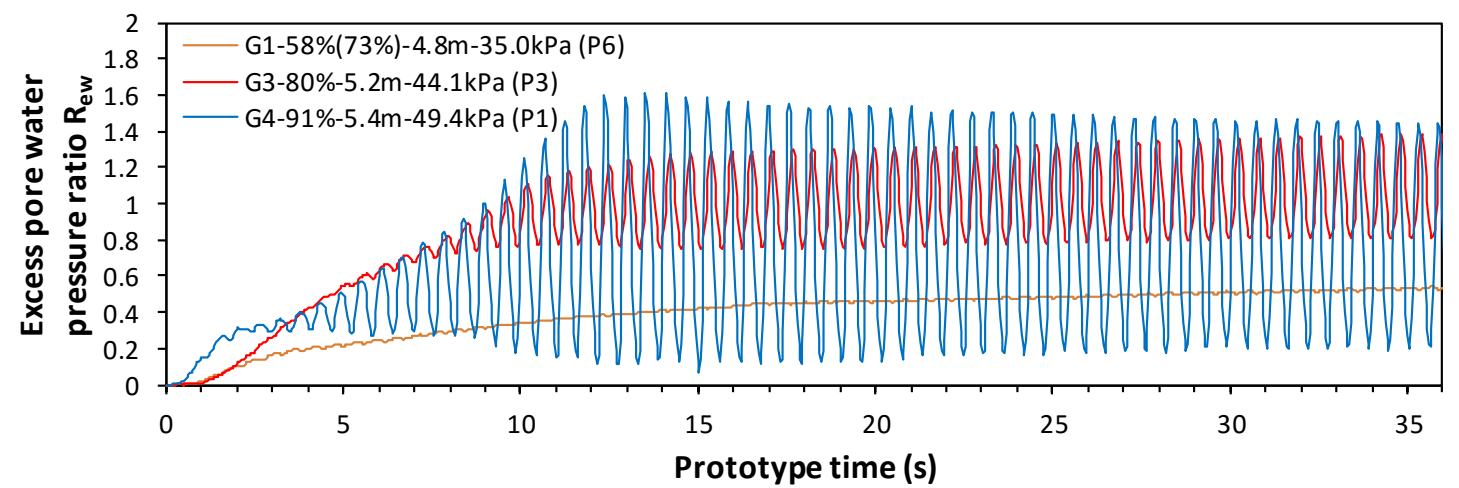

Fig. 6. Variations in the excess pore water pressure ratio $R_{e w}$ for the soil with different degree of saturation at similar initial effective vertical stresses (i.e., $35 \sim 50 \mathrm{kPa}$ ). 


\section{Concluding remarks}

To characterize the seismic behavior of partially saturated sand, centrifuge shaking table tests were performed using the IWHR horizontal-vertical centrifuge shaker. Four sandy ground models with different degree of saturation were subjected to the same horizontal-vertical shaking. The experimental results indicated that the liquefaction resistance of the partially saturated sand increases with decreasing the degree of saturation and with increasing the initial effective stress, which is consistent with the observations in element tests. In addition, as for a specific sandy ground, the boundary between the liquefied and unliquefied sand becomes deeper and deeper during shaking, which can hardly be simulated in element tests. It is proven that the centrifuge shaking table testing is an effective tool to explore the mechanisms underlying the seismic behavior of partially saturated sand.

This research was supported by National Key R\&D Program of China (SQ2017YFSF060085), National Natural Science Foundation of China (51809290) and IWHR Research and Development Support Program (GE0145B102017 \& GE0145B122019). The authors are grateful to the reviewers for their valuable comments.

\section{References}

1. M. A. Sherif, C. Tsuchiya, I. Ishibashi, J. Geotech. Eng. Div., 103, 8, 914-917 (1977)

2. R. Chaney, Earthq. Eng. Soil Dyn., 1, 342-358 (1978)

3. Y. Yoshimi, K. Tanaka, K. Tokimatsu, Soils Found., 29, 3, 157-162 (1989)

4. M. Okamura, Y. Soga, Soils Found., 46, 5, 695-700 (2006)

5. K. Konagai, J. Johansson, P. Mayorca, T. Yamamoto, M. Miyajima, R. Uzuoka, and H. Fukuoka, J. Jap. Ass. Earthq. Eng., 2, 1, 1-15 (2001)

6. R. Uzuoka, N. Sento, M. Kazama, T Unno, Soils Found., 45, 4, 149-163 (2005)

7. T. Unno, M. Kazama, R. Uzuoka, N. Sento, Soils Found., 48, 1, 87-99 (2008)

8. Y. J. Hou, X. D. Zhang, Z. P. Xu, et al., Performance of horizontal and vertical 2D shaker in IWHR centrifuge. In Proceedings of the 8th International Conference on Physical Modelling in Geotechnics (ICPMG2014), Perth, Australia, 207-213 (2014)

9. A. W. Bishop, G. E. Blight, Géotechnique, 13, 3, 177197 (1963) 